\title{
Moda, imagem e consumo: editoriais de moda como estratégia de comunicação para marcas
}

Letícia Casagrande Dal Bello

Mestranda, Universidade do Estado de Santa Catarina Orcid: 0000-0003-4046-5497 / lattes

Murilo ScOz

Doutor, Universidade Federal de Santa Catarina Orcid: 0000-0003-0189-3368 / lattes

\section{Lucas da Rosa}

Doutor, Universidade do Estado de Santa Catarina Orcid: 0000-0002-8429-2754/ lattes

Icléia Silveira

Doutora, Universidade do Estado de Santa Catarina Orcid: 0000-0003-4493-9768/ lattes

\section{Sandra Regina Rech}

Doutora, Universidade do Estado de Santa Catarina Orcid: 0000-0002-0062-6914/ lattes 


\title{
Moda, imagem e consumo: editoriais de moda como estratégia de comunicação para marcas
}

\begin{abstract}
RESUMO
O presente artigo visou abordar o tema dos editoriais de moda como estratégia de comunicação e consumo para marcas. Traz um apanhado geral sobre consumo e comunicação de moda, bem como uma explicação sobre o que são editoriais, como estes são realizados e para que servem. O artigo foi pautado bibliograficamente em diversos autores com o intuito de esclarecimento a respeito da área e do potencial comunicativo dos editoriais para marcas de moda.
\end{abstract}

Palavras-chave: editorial de moda. Imagem. Comunicação. Consumo. 


\title{
Fashion, Image, and Consumerism: fashion editorials as a communication strategy for brands
}

\begin{abstract}
This article aimed to address the theme of fashion editorials as a communication strategy and consumption for brands. Brings a general overview on consumption and fashion communication, as well as an explanation of what are editorials, how these are made and for what they serve. This article was based on the bibliography of several authors in order to clarify the area and the communicative potential of editorials for fashion brands.
\end{abstract}

Keywords: Fashion editorial. Image. Communication. Consumption. 


\title{
Moda, imagen y consumo: las editoriales de moda como estrategia de comunicación para las marcas
}

\begin{abstract}
O
Este artículo tuvo como objetivo abordar la temática de las editoriales de moda como estrategia de comunicación y consumo de las marcas. Proporciona una visión general del consumo y la comunicación de la moda, así como una explicación de qué son las editoriales, cómo se hacen y para qué sirven. El artículo fue referenciado bibliográficamente por varios autores con el fin de esclarecer el ámbito y el potencial comunicativo de las editoriales para las marcas de moda.
\end{abstract}

Palabras clave: editorial de moda. Imagen. Comunicación. Consumo. 


\section{INTRODUÇÃO}

Entre as diferentes formas de apresentação de conteúdos de moda, os editoriais fotográficos destacam-se por sua relevância na comunicação das marcas. Com o intuito de promover não apenas produtos, mas o estilo de vida e os conceitos por trás das coleções, os editoriais envolvem montagens fotográficas detalhadamente planejadas, grande refinamento técnico e elevados investimentos em produção. Assim, mobilizam equipes altamente especializadas e costumam envolver profissionais reconhecidos, consagrados tanto no campo da moda quanto em diferentes domínios da arte, que oferecem suas visões e suas perspectivas estéticas aos editoriais. Neste sentido, as produções associam as estratégias das marcas às visões dos criadores, o que implica um caráter conceitual e uma prevalência da função estética. Variando com relação às temáticas, às locações, aos personagens e aos elementos cênicos adotados, pode-se afirmar que os editoriais de moda apresentam-se como discursos, ou seja, como arranjos que guardam alinhamento interno e que, por tal característica, podem ser tomados por sua natureza narrativa.

No universo da moda é perceptível a importância de uma gestão de comunicação integrada e com nível de acabamento gráfico elevado, o que propicia a consolidação das marcas no mercado, aumento das vendas e, a longo prazo, crescimento corporativo. Diante disso, o objetivo geral deste artigo é discorrer sobre a produção dos editoriais de moda como estratégia de comunicação para marcas, abordando seu funcionamento e objetivos. Nesse sentido, descreve-se como se desenvolve tal prática, com o intuito de fortalecer a produção de conhecimentos científicos a respeito do assunto. Como Façanha e Mesquita (2012, p. 13) apontam sobre a moda, "por se tratar de uma área relativamente nova, tanto 
em termos de atividade profissional quanto em relação ao ensino e à pesquisa, pode-se dizer que a produção teórica é emergente".

Tesser (2012) diz que quem compra moda, compra imagem, e que a propaganda de moda apresenta diferentes propostas e linguagens de acordo com cada marca, despertando a atenção do seu consumidor. Logo, a justificativa da escolha dessa temática se dá pela necessidade de explicitar os modos de valorização dos produtos do sistema da moda, visto que a construção de imagens e discursos visuais pode ser considerada uma das formas de comunicação mais diretas e eficazes das marcas com os consumidores. Potencializada pelo advento das mídias sociais, este processo é marcado pela alta velocidade de circulação das informações, pelo imediatismo e pela efemeridade, traços relacionados diretamente com o consumo dos produtos da moda. Desta feita, acredita-se que ao implementar uma boa comunicação por meio da produção de imagens, pode-se qualificar o processo de consolidação das marcas perante o público, com vistas ao incremento das vendas e ao crescimento no mercado.

Quanto aos procedimentos metodológicos, e tomando como base a classificação proposta por Marconi e Lakatos (2010), Gil (2010) e Goldenberg (1999), este artigo caracteriza-se como Básico, por não possuir aplicação prática em busca do conhecimento aqui reproduzido; Qualitativo, pois seu foco é o processo e seu significado; Descritivo, por buscar compreender as relações que ocorrem entre os assuntos abordados; e de caráter Bibliográfico, pois é pautado em conteúdo teórico aprofundado ao longo do texto por meio do ponto de vista de diversos autores, correlacionando conceitos e ideias para que se possa gerar uma melhor compreensão do assunto. 


\section{FUNDAMENTAÇÃO TEÓRICA}

\subsection{Afinal, o que é um editorial de moda?}

No campo da moda, pode-se definir um editorial como sendo uma produção fotográfica que visa transmitir uma mensagem através dos looks (composição de roupas, calçados e acessórios), auxiliada pela ambientação, casting (seleção de modelos), expressão, poses, e outros elementos que integram o cenário criado para registro (RONCOLETTA, 2011). Nestes termos, e na perspectiva também aqui adotada, o editorial pode ser compreendido como uma ou mais imagens fotográficas que buscam apresentar os produtos de moda.

Joffily (1991, p. 13) traz que o valor do editorial se dá por comunicar ao público as atualizações da indústria, além de "acompanhar, pelo prisma da moda, a flutuação dos comportamentos, a mudança nas correntes socioculturais." Isto significa que o editorial pode não somente apresentar o que há no mercado, mas "apontar as ligações da moda num sentido mais amplo com a atualidade sócio-cultural" (idem, p. 87). Em outros termos, o conjunto de imagens alinhadas num editorial tem a possibilidade de refletir criticamente sobre 0 horizonte estético e social, servindo como uma ferramenta de análise e percepção de valores vigentes em cada contexto. Considerando a potência comunicativa das imagens, pode-se constatar a relevância de uma boa comunicação visual para as marcas, potencializando sua divulgação, apreensão por parte do consumidor e, consequentemente, sua comercialização.

Independente do estilo, a roupa por si só tem a função primária de cobrir o corpo, ou seja, de vestir os indivíduos dentro de seu espaço social. Joffily, e Andrade (2011) dizem que a roupa conta de seu tempo, lugar e contexto, seja qual for sua complexidade. Como artefato, Crane (2006, p. 22) diz 
que as roupas " 'criam' comportamentos por sua capacidade de impor identidades sociais e permitir que as pessoas afirmem identidades sociais latentes", exprimindo seus gostos, costumes e status. Portanto, pode-se afirmar que ao vestir uma roupa, ocorre uma construção social por parte do indivíduo, que busca manipular a percepção que os demais tem dele através de suas práticas vestimentares - cada uma carregando diferentes significados de acordo com quem a veste, quem a analisa, a combinação com as demais peças e o contexto onde está inserida.

Já em uma fotografia, como coloca Marra (2008, p. 54), a roupa "responde somente aos critérios e às características estéticas, torna-se puro exercício de estilo e se oferece à fruição livre de toda obrigação prática; as cores, as formas tornam-se completamente autônomas." Aqui, expande-se a ideia inicial de cobrir o corpo e de impor-se socialmente e entra-se no plano da delimitação de uma identidade social, o que passa pela construção de uma narrativa, ampliando os horizontes do vestuário como necessidade na direção de uma lógica subjetiva e relacional, em que os artefatos da moda se configuram como objetos de desejo. Pereira Filho (2012) reforça esta ideia dizendo que a fotografia de moda vai além da moda e manipulação, demonstrando comportamentos de consumo, sendo a moda um dos mais significativos elementos de leitura de tempo, cultura e comportamento social.

Crane (2006) fala que as fotografias de moda sujeitam-se a diversas interpretações por apresentam diferentes identidades que se cruzam e refletem a complexidade de se autodefinir. São as sutilezas embutidas nas fotos, seja nas roupas, na pose, na expressão ou na ambientação que acabam por dar sentido ao que se constrói, compondo um universo de construção de sonhos e desejos, manipulando o consumidor ao criar essa aparente necessidade de encaixar- 
se em um modelo vigente de vestuário e comportamento, e movimentando, assim, o consumo de moda.

\title{
2.1.1 Uma breve história dos editoriais
}

Com o objetivo de refletir sobre a noção de editoriais fotográficos no contexto contemporâneo, parece fundamental compreender o papel dos planos de comunicação na lógica da moda. Por esta razão, é necessário situar estas ações numa perspectiva histórica, evidenciando seu alinhamento às dinâmicas mercadológicas e culturais emergentes com a própria indústria da moda. Nestes termos, Sant'anna explica que

\begin{abstract}
A moda, como a conhecemos hoje, nasce no século $X X$, no pós-guerra, e é uma indústria de alma capitalista. Tem como princípio desenvolver os caracteres da efemeridade, mutação constante, ostentação de riqueza e glamour, explorando e investindo na formação de grupos de consumidores. Mesmo existindo a cobrança de individualidade, os indivíduos querem sentir identificação com algum grupo. Podemos até mesmo afirmar que a moda produz e vende identidades pré-fabricadas. $E$ a indústria da moda captura, modela e coloca no mercado essas identidades estilizadas. (SANT'ANNA, 2012, p. 131)
\end{abstract}

Considerando os fatores apontados pela autora, é possível compreender o papel das produções editoriais na consolidação dos discursos da marca, o que se articula ao domínio da fotografia de moda. Marra (2008) observa que a atividade fotográfica vinculada à moda se inicia por volta da década de 1890, quando a fotogravura passa a permitir a impressão de foto e texto em uma mesma página. Em 1892, de acordo com o autor, aparece pela primeira vez a reprodução direta de uma fotografia na revista La Mode Pratique, de Paris.

Já no século XX, na década de 1920, segundo Bracchi (2012), fotos de pessoas da alta sociedade começaram a ser 
publicadas em revistas relacionadas a estilo, moda e decoração. "Já nessa época, as roupas mostradas comunicavam um valor não apenas material, mas também simbólico e identitário, corporificando memórias e relações sociais." (STALLYBRASS, 2000 apud BRACCHI, 2012, p. 178) Pode-se observar, portanto, que desde seu princípio a fotografia de moda tem um caráter de significação, indo além da pura representação do vestuário.

No final da década de 1960 e início da década de 1970, "a partir do fortalecimento da indústria têxtil no Brasil, do crescimento do comércio da moda e da profissionalização dos veículos de mídia, o mercado demandava cada vez mais serviços de produção de moda." (JOFFILY; ANDRADE, 2011, p. 26). Já se buscava nesse período um profissional - embora ainda não houvesse reconhecimento da profissão propriamente dita - que tivesse habilidade, experiência e conhecimento, destacando-se no mercado e elevando o nível das produções fotográficas. Svendsen (2010) comenta que em 1984 o fotógrafo da Vogue, Richard Avedon, declarou que seu papel consistia em vender sonhos, não roupas.

Pereira Filho (2012, p. 305) observa que, na década de 1990, a moda passou a propor maior individualismo e que "a expressão pessoal tornou-se mais importante do que as próprias roupas. Entrou em cena o stylist (antes chamado de produtor de moda)." Segundo o autor, foi este profissional que passou a se responsabilizar pela criação de imagens de moda, atuando juntamente com os estilistas e criadores das marcas de maior destaque. Braga conta que nesse período

Surgiram os novos profissionais de moda que são verdadeiros criadores de conceitos, idéias e principalmente imagens. Aí estava um chavão para decifrar a moda do final dos anos 90 e da atualidade: a imagem na maioria das vezes era e ainda é mais importante que o próprio produto. Costumava-se vender um conceito, seja da marca ou de uma coleção, através de imagens, às vezes sem aparecer a roupa, e o 
consumidor se convencia que não podia viver sem tais referências. Ótima fórmula. Além do estilista propriamente dito, surgiu o 'stylist' para pesquisar e orientar todo o desenvolvimento de ideias e consequentemente produtos. $\mathrm{O}$ fotógrafo de moda também ganhou status criando através das lentes o seu imaginário, seja aparentemente real, ou especialmente surreal. Bruce Weber e Oliviero Toscani foram grandes nomes do início da década de 90 e mais adiante sobressaíram Mario Testino e David Lachapelle; entre outros, obviamente. (BRAGA, 2004, p. 103-104)

Passou-se, nestes termos, do "vender roupa" para o simbólico de "vender sonhos". As pessoas são assim interpeladas por discursos imagéticos baseados na ideia de que os produtos não são apenas necessários, mas mais exatamente verdadeiros objetos de desejo. Com as novas possibilidades de linguagem introduzidas pelas tecnologias digitais, e sobretudo com as dinâmicas das redes sociais, esse fator tem se tornado ainda mais influente. Pereira Filho (2012, p. 307) diz que "na verdade, a introdução da tecnologia digital pode ser considerada uma mudança crucial na fotografia de moda, pois seu uso passou a colaborar de modo inventivo nas narrativas de editoriais." Expandem-se os horizontes, surgindo novas possibilidades de registro e divulgação de imagens, assim como do consumo em si, podendo-se adquirir os produtos de maneira quase instantânea através de poucos toques em uma tela de computador ou celular.

\subsubsection{O Stylist}

Ao tratar do termo stylist em si, é importante definir sua relação com o produtor de moda. Frange (2012) esclarece que fora do Brasil, stylist e produtor são o mesmo, e na tradução do termo do inglês para português, um ainda equivale ao outro, porém na prática no Brasil são delimitadas diferenças: "em nosso país existe uma pirâmide hierárquica na qual o 
stylist é o criador do conceito da imagem de moda, e o produtor de moda é o profissional que vai para as ruas, que encontra as peças e as coordena." (FRANGE, 2012, p. 34) Desse modo, de acordo com essa hierarquia, o stylist seria o responsável pela concepção, pela ideia, e o produtor se encarrega de concretizá-la.

Holzmeister (2012, p. 43) conta que no início da década de 80, "a revista Moda Brasil inaugurou fase revolucionária na produção dos editoriais de moda, abrindo espaço para novos profissionais: o fotógrafo e o produtor de moda." Ainda, a autora (2012, p. 45) explica que iniciou-se a profissão como produtor de moda, e o profissional teve posteriormente o termo stylist incorporado, "significando um degrau a mais. A partir de então, esse profissional passou a assinar a concepção de um ensaio de moda - no lugar da editora geral de uma revista - , gerenciando as atividades do produtor e do assistente de produção", reforçando a hierarquia apresentada anteriormente.

$\mathrm{Na}$ área de atuação, pode-se definir que o stylist é o profissional responsável pelo styling, ou seja, pela criação de um conceito que unirá elementos de moda em uma imagem, que conta uma história com a intenção de cativar o públicoalvo, despertando desejo de pertencimento a um grupo através daquela peça, daquele look e daquela marca (FRANGE, 2012). Ao combinar elementos como roupas, calçados e acessórios dentro de uma ambientação previamente pensada e estruturada, embutindo significados em detalhes, poses e expressões, o stylist cria uma narrativa que tem o poder de manipular o consumidor, despertando 0 desejo de consumo.

É importante que haja "uma ligação entre o público, a representação e a realidade, mesmo que esta seja completamente desvinculada do âmbito corporal, estabelecida no imaginário." (FRANGE, 2012, p. 21-22) 0 
stylist é, nesse caso, responsável por criar essas conexões, não somente com o público, mas também com a coleção e a marca. Garcia e Miranda (2005) dizem que através da combinação dos looks dentro de uma temática, o stylist estabelece um padrão de uso que pode-se chamar por tendência, que manipula o consumidor a desejar algo sempre novo, submetendo-o a modificações constantes para que permaneça em sincronia com o que está em voga. A tendência faz com que o consumidor crie uma necessidade de consumo por aquele objeto que oferece um certo status e permite, mesmo que apenas no imaginário, atingir o ideal que almeja. Aí, vê-se refletido o ciclo da moda de obsolescência planejada, para que o ritmo de consumo permaneça constante. Sobre o assunto, as autoras explicam que a obsolescência planejada é um

[...] processo ideológico que imerge a propriocepção dos consumidores nos significados culturais e ideais sociais, promovendo estado perpétuo de insatisfação com o estilo de vida e com a aparência física do momento. Sendo assim, a análise do ciclo de vida da moda e dos movimentos de adoção dos diferentes estilos de vestir é fundamental para o desenho das estratégias mercadológicas e de comunicação, pois visa a determinar a duração de uma tendência e prever a introdução de novos estilos. Qualquer que seja o segmento de produto ou serviço que se tenha em mente, o fenômeno da moda está ligado à introdução de novos produtos e à difusão da inovação (GARCIA; MIRANDA, 2005, p. 67).

Assim, fica em evidência que a moda é frequentemente pautada pela mudança de tendências de forma a introduzir novos produtos ou até reintroduzir atualizações de produtos anteriores, incentivando o consumo.

Após esta descrição sobre o profissional responsável pelo styling, surge a questão: como ele realiza sua função? Ferraz (2012, p. 64) diz que "[...] embora parte dos profissionais que atuam nessa área tenham conquistado um papel central na 
indústria da moda, são raros os estudos e pesquisas sobre a atividade e pouco se conhece sobre a metodologia de trabalho do profissional stylist." Entretanto, Mesquita (2012) consegue esclarecer essa questão ao dizer que para estar apto a exercer sua função transformando uma ideia em imagem concreta, o stylist deve circular entre diversos campos de conhecimento, como metodologia de pesquisa criativa, tendências de moda, comportamento, história, cultura, estética, além de noções de produção, comunicação e marketing, sendo capaz de dialogar com outras áreas relacionadas à sua, como design digital, fotografia e artes plásticas. Entende-se, portanto, que o stylist que consegue ser um profissional multidisciplinar, capaz de absorver, combinar e praticar conhecimentos de diversas áreas de forma tende a desempenhar seu papel com maestria.

\subsubsection{Desenvolvimento de um editorial}

Na área da moda, cada categoria de trabalho exige uma equipe, e no caso dos editoriais, não é diferente. Além do stylist, podem-se destacar outros profissionais-chave que contribuem para a realização de um editorial: o fotógrafo de moda, o beauty artist (profissional da beleza), a modelo, o iluminador, o designer de produção, o casting, entre outros. Assim como as roupas e a ambientação, a equipe deve ser selecionada já considerando o conceito a ser retratado, para que o estilo do fotógrafo e o perfil da(s) modelo(s) sejam condizentes com a proposta. Dependendo do porte do trabalho (ou job, como é popularmente chamado), mais profissionais podem ser necessários, como camareiras, serviço de catering (alimentação), assistentes e até mesmo equipes inteiras de apoio aos profissionais citados acima que complementam e auxiliam as funções que venham a ser requisitadas. 
Vale ressaltar, aqui, um breve esclarecimento a respeito do beauty artist. Ele pode ser somente um único profissional que atue como cabeleireiro e maquiador, ou dois profissionais, cada um atuando em uma função, sendo o hairstylist o cabeleireiro e o make up artist o maquiador. Holzmeister (2012, p. 29) explica que utiliza-se tais nomenclaturas porque "ao contrário dos profissionais que trabalham em salões de beleza, a missão deles é construir um personagem fashion, utilizando produtos e mecanismos bem diferentes daqueles usados até mesmo para a mais sofisticada das festas." É, portanto, necessário um repertório diferente do profissional comum da área de beleza.

O fotógrafo de moda também costuma possuir um repertório próprio da área, diferenciando-se dos profissionais que atuam em outros ramos da fotografia. Técnicas específicas de iluminação e composição de cena, estudos na área de moda, tendências e comportamento, direcionamento de modelos e um olhar criativo apurado são características desejáveis nesse profissional.

Quanto à modelo, esta costuma ser escolhida a partir do briefing de acordo com suas características físicas, de forma a compor a personagem criada para o editorial, e pode ser contratada diretamente ou através de agências especializadas. Há situações nas quais se utilizam celebridades, como atrizes, cantoras, personalidades da mídia e atualmente também as chamadas influencers, pessoas comuns que ganharam destaque nas redes sociais com conteúdos diversos sobre seu cotidiano, moda, comportamento, estilo de vestir, entre outros. A escolha de qual "categoria" de modelo será utilizada pode se dar de acordo com a proposta do conceito, porte do trabalho ou meios de veiculação de cada editorial.

Tendo a equipe sido estabelecida, foca-se na criação da imagem. O tema pode ser conversado entre os membros da 
equipe para alinhamento de ideias, mas fica a cargo do stylist a composição dos looks e ambientação. Sant'anna explica que

A criação de imagem de moda nasce de uma investigação, baseia-se na produção de visualidades que não mais partem da imitação da realidade, mas sim de um conceito. Afinal, todo o processo criativo surge de um dado mental. Dessa maneira, ordenar as ideias, debate-las antes de começar a produção da imagem é fundamental. A produção de imagem de moda começa, portanto, no debate das ideias que devem ser expostas. Delimitar o tema, levantar materiais e praticar a documentação dos estudos (resumos, resenhas, fichamentos, desenhos, materiais, fotografias, padrões, etc.), enfim, guardar e ordenar tudo o que vai alimentando esse estudo é base fundamental desse processo. (SANT'ANNA, 2012, p. 135)

Em outras palavras, a criação de imagem parte da definição de temas e do acerto entre os profissionais envolvidos sobre o caminho a seguir. É necessário que este seja delimitado, estudado e organizado, para que não se perca o foco ao longo do processo. É importante que, durante a preparação e realização do editorial, sejam periodicamente revisitadas as referências e o escopo do projeto para garantir que está de acordo com o que foi planejado - ferramentas como moodboards e checklists, por exemplo, podem ser instrumentos valiosos para tal. Ramalho e Oliveira (2007) reforça que é fundamental haver uma unidade da marca, mantendo a coerência nos discursos de cada manifestação desta, para que não haja contradições.

Holzmeister (2012, p. 49) traz que atualmente "a captação das imagens de backstage durante a realização de sessões fotográficas para catálogos e editoriais tem crescido a ponto de se tornar quase obrigatória como ferramenta de marketing." O público não consome somente a imagem final, mas quer engajar-se na construção, vendo o passo-a-passo e a realidade por trás do que está sendo feito. É natural, ainda, que surjam alterações no decorrer do editorial, tanto na 
preparação quanto na execução do mesmo, tendo os profissionais que lidar com diversos imprevistos e, por isso, é preciso estar preparado para qualquer situação que possa ocorrer. Além disso, são recorrentes os ajustes na fase de pós-produção, etapa que envolve outros profissionais e que se encarregam de alterar elementos diversos e corrigir aspectos visuais das imagens capturadas, sempre no sentido de garantir que o conceito da produção seja preservado.

\subsection{Comunicação de marca e consumo de moda}

As marcas de moda são capazes de refletir o indivíduo e seu jeito de ser, agir e pensar ao contar histórias, criadas com a intenção de identificação do consumidor, que se deixa influenciar por elas. Proni (2008) fala que todas as manifestações da marca são instrumentos de sua comunicação: nome, logotipo, produto, estilista, desfile, publicidade - site, vídeos, fotografias, entrevistas, reportagens -, pontos-de-venda, lojas etc. Estando relacionado com a marca, pode ser considerada uma manifestação e um instrumento de comunicação da mesma, direta ou indiretamente. Tesser (2012) afirma que toda a comunicação da marca deve manter uma mesma identidade para que seja forte e consistente, e que, independente do veículo em que se anuncia, o conceito deve ser mantido sempre o mesmo.

Duque-Estrada (2011, p. 327) explica que "de um modo geral, as marcas brasileiras ainda não construíram seus mundos particulares, suas identidades de marca de forma consistente." Considerando que o número de marcas de moda é crescente, e muitas vezes oferecem produtos semelhantes, com a mesma fonte de inspiração e matéria-prima, a construção da imagem torna-se um grande diferencial 
competitivo (TESSER, 2012), posicionando a marca diante do consumidor e atraindo seu nicho de mercado para perto de si.

Robic (2012) defende que a diferenciação de uma marca ganha poder em sua imaterialidade - que pode ser tomada aqui como o intangível, imensurável, o que a marca transmite em um nível simbólico, não palpável - , gerando uma conexão emocional com a marca como um todo, e não somente com o produto, que oferece uma conexão racional, ligada à usabilidade, necessidade e conforto. Conhecer e estrategizar a imaterialidade da marca é essencial para uma boa comunicação - e a imagem pode ser uma excelente aliada para transmitir os símbolos do imaterial. Tesser (2012, p. 209) afirma que "uma imagem bem construída pode dizer tudo sobre uma marca: como é, o que oferece e para quem. Conceito, marca e estilo de vida - essa é a mensagem a ser transmitida; a roupa fica em segundo plano."

O consumo de moda é baseado em símbolos, e é essa capacidade simbólica que tem o poder de fazer o consumidor atrelar-se a uma determinada marca em face das demais, não adquirindo o objeto por si só, mas pelo que ele simboliza. 0 comportamento de consumo pode ser explicado pela necessidade do indivíduo de expressar significados através de produtos adquiridos que comunicam a mensagem de como o indivíduo se percebe ou deseja ser percebido (MIRANDA, 2008). A relação do aspecto simbólico atribuído pela marca com os interesses do público consumidor é a premissa básica de uma publicidade bem-sucedida. Em termos de editorial de moda, Bracchi (2012, p. 177) fala que "as cenas criadas deixam para nós um papel a desempenhar e instruções sobre como sentir e viver o impacto criado pelo mundo da moda no público consumidor." O conceito do produto, o tema da coleção, a essência da marca e as imagens criadas para comunicação devem estar em sintonia para conseguir atingir as necessidades simbólicas do consumidor. 
O consumidor não consegue distinguir entre os seus próprios sentimentos sobre o produto e as suas crenças sobre como é visto pelos outros. Desta feita, seu comportamento é coerente e consistente com a imagem do que acredita que é, no seu autoconceito real, ou como gostaria de ser, no seu autoconceito ideal. Neste caso, os produtos são como instrumentos que ajudam a realizar o transporte do "eu real" para o "eu ideal". Podemos entender que os produtos expressam as construções do próprio eu: alguém se percebe, na sua preferência de compra, como assemelhado a objeto específico, logo se imagina na ótica do outro e como se acredita visto por ele. O eu não é desenvolvido a partir de processo pessoal ou individual, mas envolve todo o processo da experiência social. $\mathrm{Na}$ aferição das realizações dos outros, o sujeito desenvolve a sua própria autopercepção, ele percebe-se como acredita que é percebido (GARCIA; MIRANDA, 2005, p. 25-26).

Se o produto, ou roupa, em si, já carrega um rol de símbolos que permite ao indivíduo identificar-se e expressarse, a composição de diversas peças de roupa em um look pode atribuir um conjunto de valores que vem a ganhar um novo sentido ao serem combinados, criando uma narrativa que pode expressar tanto quem se é, quanto quem se pretende ser. Tomando isso como verdade, um editorial, ao fazer essa composição de forma planejada e inserindo-a em um ambiente criado ou pensado para estabelecer e reforçar a narrativa, pode intensificar o nível de significação do conjunto, elevando-o a outro patamar e fazendo uma conexão instantânea com o público.

Robic (2012, p. 229) reforça que é importante planejar os elementos que irão compor o imaterial ou imaginário da marca, pois isso permite a formação de estruturas consistentes de comunicação, gerando vínculos afetivos e criativos mais duradouros com o indivíduo. Crane (2006) propõe que a escolha dos indivíduos por determinado produto se dá por avaliação e estimativa constante de bens de consumo de acordo com o potencial que estes têm de contribuir para a imagem que buscam projetar. A 
autopercepção do indivíduo motiva seu comportamento de consumo, fazendo com que adote produtos cujo símbolos possam expressar a imagem que desejam, refletindo sua cultura, localização no espaço e tempo, tendências e mudanças.

A resposta ao incentivo de consumo pode ser relacionada também às sugestões ao redor do indivíduo que reforçam a satisfação que a compra trará. Assim, pode-se observar que certos estímulos tendem gerar o mesmo tipo de resposta - o que pode ser chamado de "tentação" de seguir adquirindo produtos de determinada marca por já ter tido uma experiência anterior positiva. Garcia e Miranda (2005) consideram que se trata de uma avaliação que leva o consumidor a aproximar-se ou afastar-se de algo, composta por três componentes: cognitivo (crenças), afetivo (sentimentos) e aprendido (intenções comportamentais). Tal classificação aproxima-se dos níveis do Design Emocional, proposto por Norman (2008), composto pelos níveis Visceral, Comportamental e Reflexivo, sendo estes equivalentes ao impacto estético imediato causado pelo artefato, a sua usabilidade e a significação que carrega, respectivamente. Svendsen (2008) coloca que o valor simbólico substitui o valor de utilidade, explicando que a relação do usuário com os objetos é cada vez menos referente ao uso. O autor reforça que valores como utilidade e estética são importantes, mas que é a diferenciação simbólica que possui a capacidade de justificar o valor econômico de um objeto.

\section{ALGUNS APONTAMENTOS SOBRE A COMUNICAÇÃO DE MODA}

O consumidor de moda pode ser considerado um intérprete de códigos capaz de discriminar entre as alternativas, identificando e optando pelos produtos ideais 
para expressar determinada ideia ou imagem. O consumo, então, torna-se uma forma de desempenhar uma performance, visto que o consumidor busca projetar identidades constantemente em mudança de acordo com seus próprios parâmetros, assim como as flutuações da moda, sempre tendo em vista as dinâmicas de interação que estabelece em seu contexto social. A variedade de opções de estilos permite que 0 indivíduo faça escolhas mais significativas, já que através destas afirma sua autopercepção, a qual torna-se uma preocupação importante considerando que o mesmo reavalia constantemente o que ocorre ao seu redor, seu posicionamento perante tais fatos e, consequentemente, sua identidade ideal para o momento, alternando o grau de relevância de diversos fatores de acordo com suas percepções e experiências passadas e presentes. Desta forma, o indivíduo constrói sua identidade pessoal única e diferenciada. Curiosamente, Battistelli (2008) comenta que uma moda é adotada para diferenciar-se, mas justamente por isso se difunde e acaba sendo assimilada, condenando-se à constante reinvenção.

É neste cenário que estão inseridas as imagens dos editoriais de moda. Pôde-se constatar que elas oferecem um caminho de extrema relevância estratégica para os planos de comunicação das marcas, constituindo-se como ferramenta indispensável para a construção dos universos simbólicos das mesmas. Na perspectiva aqui adotada, pôde-se observar a importância da estruturação de discursos claros e alinhados ao planejamento conceitual das campanhas, o que reitera a primazia dos estudos sobre os conteúdos narrativos veiculados. Através de elementos simbólicos de grande interesse ao seu público-alvo, as marcas buscam envolver seus interlocutores para que se identifiquem e se afirmem como clientes da marca. Para que esta comunicação seja eficaz, o discurso da marca deve estar alinhado com o seu 
consumidor, e para tal, uma equipe qualificada se faz relevante na concepção do editorial.

Vale reforçar que, para uma marca de moda, "a propaganda estimula e motiva as vendas, mas, para alcançar os objetivos desejados, é preciso que ela esteja associada a outros fatores: qualidade, apresentação atraente, bom atendimento, serviços, preços, facilidade de distribuição, etc" (TESSER, 2012, p. 209). Assim, apesar da imagem ter um forte valor na consideração do consumo, ela não é o único elemento a agir nesse nível: o produto, bem como o restante dos elementos imateriais da marca, precisam atender a alguns requisitos básicos essenciais que o torne agradável ao público, como agradabilidade estética e usabilidade, atendendo necessidades que vão além da simbolicidade.

\section{CONSIDERAÇÕES FINAIS}

As características do consumo de moda estão ligadas à valores intrínsecos, preferências pessoais, autoconceito e a necessidade de impor-se socialmente. Questões como a obsolescência planejada e a renovação de tendências também se fazem relevantes nesse âmbito. Pode-se assumir, a partir do que foi apresentado neste artigo, que o consumidor não adquire o produto ou marca apenas por questões de necessidade, mas sim pela imagem percebida de um ideal que almeja e que estes representam. O consumo simbólico segue sendo altamente presente na moda, devido à capacidade presente nas roupas de comunicação não-verbal, transmitindo valores, ideais, cultura, status e diversos outros posicionamentos sociais. Sendo assim, reconhece-se que um editorial de moda, através da composição dos looks em uma ambientação e posicionamento estrategicamente planejados, é capaz de criar um caminho de relação positiva entre o consumidor e a marca, solidificando-a e fomentando o 
consumo da mesma. Acredita-se que, ao utilizar da imagem de moda no formato de editorial como ferramenta estratégica de comunicação para as marcas, pode-se aproximar e criar vínculos com o consumidor, criando identificação através dos simbolismos presentes em seu imaterial, influenciando-o e manipulando-o, levando finalmente ao consumo.

\section{REFERÊNCIAS}

BATTISTELLI, Piergiorgio. A psicologia e a moda. In: SORCINELLI, Paolo (org.); MALFITANO, Alberto; PRONI, Giampaolo (cols.). Estudar a Moda: corpos, vestuários, estratégias. São Paulo: Editora Senac São Paulo, 2008.

BRACCHI, Daniela. Contribuições da semiótica para a fotografia de moda. In: FAÇANHA, Astrid. MESQUITA, Cristiane. Styling e Criação de Imagem de Moda. São Paulo: Editora Senac São Paulo, 2012.

BRAGA, João. História da moda. São Paulo: Editora Anhembi Morumbi, 2004.

CRANE, Diana. A moda e seu papel social: classe, gênero e identidade das roupas. São Paulo: Editora Senac São Paulo, 2006.

DUQUE-ESTRADA, Ana Cristina Puglia. Corpo, vestuário e atitude na construção d marcas de moda feminina. In: CASTILHO, Khatia. DEMETRESCO, Sylvia (orgs.). Consumo: práticas e narrativas. São Paulo: Estação das Letras e Cores, 2011.

FAÇANHA, Astrid; MESQUITA, Cristiane. Styling e criação de imagem de moda. São Paulo: Editora Senac São Paulo, 2012.

FERRAZ, Marilia F. Pesquisa e criação de imagem de moda: uma abordagem metodológico. In: FAÇANHA, Astrid. MESQUITA, Cristiane. Styling e Criação de Imagem de Moda. São Paulo: Editora Senac São Paulo, 2012.

FRANGE, Cristina. Styling: mapeando o território. In: FAÇANHA, Astrid. MESQUITA, Cristiane. Styling e Criação de Imagem de Moda. São Paulo: Editora Senac São Paulo, 2012.

GARCIA, Carol; MIRANDA, Ana Paula de. Moda é Comunicação: experiências, memórias, vínculos. São Paulo: Editora Anhembi Morumbi, 2005.

GIL, Antonio Carlos. Como elaborar projetos de pesquisa. 5. ed. São Paulo: Atlas, 2010.

GOLDENBERG, Mirian. A arte de pesquisar: como fazer pesquisa qualitativa em ciências sociais. 11. ed. Rio de Janeiro: Record, 2009.

HOLZMEISTER, Silvana. Styling: guia básico. São Paulo: Estação das Letras e Cores, 2012. 104 p.

JOFFILY, Ruth. O Jornalismo e Produção de Moda. Rio de Janeiro: Nova Fronteira, 1991. 
JOFFILY, Ruth; ANDRADE, Maria de. Produção de moda. Rio de Janeiro, Senac Nacional, 2011.

MARCONI, Marina de Andrade; LAKATOS, Eva Maria. Técnicas de pesquisa: planejamento e execução de pesquisas, amostragens e técnicas de pesquisa, elaboração, análise e interpretação de dados. São Paulo: Atlas, 2010.

MARRA, Claudio. Nas sombras de um sonho: história e linguagem da fotografia de moda. São Paulo: Editora Senac São Paulo, 2008.

MESQUITA, Cristiane. Para além do design: styling e criação de imagem de moda. In: FAÇANHA, Astrid; MESQUITA, Cristiane. Styling e Criação de Imagem de Moda. São Paulo: Editora Senac São Paulo, 2012.

MIRANDA, Ana Paula de. Consumo de moda: a relação pessoaobjeto. São Paulo: Estação das Letras e Cores, 2008.

NORMAN, Donald A. Design Emocional: por que adoramos (ou detestamos) os objetos do dia a dia. Rio de Janeiro: Rocco, 2008.

PEREIRA FILHO, Bernardo de Aguiar. Zeitgeist nas viradas dos séculos XX e XXI. In: FAÇANHA, Astrid; MESQUITA, Cristiane. Styling e Criação de Imagem de Moda. São Paulo: Editora Senac São Paulo, 2012.

PRONI, Giampaolo. A semiótica e a moda. In: SORCINELLI, Paolo (org.); MALFITANO, Alberto; PRONI, Giampaolo (cols.). Estudar a Moda: corpos, vestuários, estratégias. São Paulo: Editora Senac São Paulo, 2008.

RAMALHO E OLIVEIRA, Sandra. Moda também é texto. São Paulo: Edições Rosari, 2007.

ROBIC, Luciane Adário Biscolla. A Comunicação do Intangível: análise do elemento imaterial da marca. In: FAÇANHA, Astrid; MESQUITA, Cristiane. Styling e Criação de Imagem de Moda. São Paulo: Editora Senac São Paulo, 2012.

RONCOLETTA, Mariana. Revistas de moda sem mistérios: estruturas e abordagens. In: CASTILHO, Khatia; DEMETRESCO, Sylvia (orgs.). Consumo: práticas e narrativas. São Paulo: Estação das Letras e Cores, 2011.

SANT'ANNA, Patricia. O desafio da criação de imagem de moda em um mundo global. In: FAÇANHA, Astrid; MESQUITA, Cristiane. Styling e Criação de Imagem de Moda. São Paulo: Editora Senac São Paulo, 2012.

SVENDSEN, Lars. Moda: uma filosofia. Rio de Janeiro: Zahar, 2010. TESSER, Priscilla. História da imagem publicitária feminina na moda. In: FAÇANHA, Astrid; MESQUITA, Cristiane. Styling e Criação de Imagem de Moda. São Paulo: Editora Senac São Paulo, 2012. 